Derecho y aborto: Reforma normativa sobre su despenalización y acceso por litigio estratégico en el Perú

\author{
Beatriz Ramírez Huaroto \\ Brenda Álvarez Álvarez
}

El presente artículo reflexiona acerca de los modelos de regulación del aborto en el mundo, el debate sobre la modificación del marco legal en el Perú, los estándares internacionales sobre el uso de procesos constitucionales para el acceso a los servicios de aborto en supuestos permitidos por las leyes nacionales, y se esbozan ideas sobre la posibilidad de ampliar las causales permitidas por vía procesal constitucional.

Abogada y Magistrada en Derecho Constitucional por la Pontificia Universidad Católica del Perú.

* Abogada y candidata a Magistrada en Derecho Constitucional por la Pontificia Universidad Católica del Perú. 
Derecho y aborto: Reforma normativa sobre su despenalización y acceso por litigio

\section{Derecho y aborto: Reforma normativa sobre su despenalización y acceso por litigio estratégico en el Perú}

\section{Los sistemas de regulación del aborto en el Derecho comparado ${ }^{1}$}

Dentro de los países que criminalizan el aborto existen tres modelos:

a. La penalización total en donde el aborto es un delito en todo caso. En los países de América Latina y el Caribe está vigente en Chile, El Salvador, Haití, Honduras, Nicaragua, República Dominicana y Surinam.

b. El modelo de permisión por causales, indicaciones o excepciones en el que se incorporan ciertos supuestos en donde se permite el aborto. Las causales más comunes son la protección de la vida de las mujeres, la protección de su salud, los casos de malformaciones fetales incompatibles con la vida, la causal socioeconómica, la inseminación forzada y la violación sexual. Está vigente en Argentina, Bolivia, Brasil, Colombia, Costa Rica, Ecuador, Guatemala, Guyana, México (menos el Distrito Federal), Panamá, Paraguay, Perú, y Venezuela.

c. El modelo de permisión por plazos en el que no se penaliza el aborto en las primeras semanas del embarazo, pero sí en las etapas más avanzadas en las que el aborto es permitido por causales. Vigente en Cuba, Guyana, Guyana Francesa, México D.F., Puerto Rico y recientemente en Uruguay.

El modelo de despenalización por causales es el vigente en el Perú en el que solo es legal el aborto "practicado por un médico con el consentimiento de la mujer embarazada o de su representante legal, si lo tuviere, cuando es el único medio para salvar la vida de la gestante o para evitar en su salud un mal grave y permanente" (artículo $119^{\circ}$ del Código Penal). Este es el modelo que se está discutiendo en Chile en el que la Cámara de Diputados ha aprobado la despenalización del aborto ${ }^{2}$ en los casos de malformaciones fetales incompatibles con la vida extrauterina, embarazos producto de violación sexual, y riesgo vital presente o futuro de modo que la interrupción del

1 Se retoman consideraciones expuestas en Díaz Colchado, Juan Carlos y Ramírez Huaroto, Beatriz. El aborto y los derechos fundamentales. Análisis de la constitucionalidad de la prohibición penal de la interrupción del embarazo en supuestos de violación sexual y de malformaciones fetales incompatibles con la vida extrauterina, PROMSEX, Lima, 2013, p. 9.

2 "Chile: Cámara de Diputados aprueba el proyecto de despenalización del aborto por tres causales", BBC Mundo, 17 de marzo de 2016. Disponible en: http://www.bbc.com/mundo/noticias/2016/03/160317 chile diputados despenalizacion aborto ap

La página oficial del Gobierno de Chile sobre el proyecto de ley presentado por el Poder Ejecutivo en 2015 está disponible en http://3causales.gob.cl/

Última fecha de consulta: 30 de octubre de 2016 
embarazo evite un peligro para su vida; el debate está pendiente aún en el Senado de dicho país ${ }^{3}$.

La penalización del aborto imposibilita el acceso a una interrupción legal del embarazo; obliga a las mujeres que decidan interrumpir la gestación a someterse a procedimientos clandestinos que pondrían poner en riesgo su vida o su salud de realizarse de forma insegura. La prohibición del aborto afecta a las mujeres de forma diferenciada pues tiene un impacto más gravoso en aquellas que requieren acceso a servicios públicos de salud, como las mujeres de menores ingresos y las adolescentes.

\section{Debates legislativos sobre la despenalización del aborto en el Perú}

En los últimos 25 años las discusiones legislativas entorno a la despenalización del aborto se han centrado principalmente en la despenalización del aborto por violación.

El inciso 1 artículo $120^{\circ}$ del Código Penal establece que "el aborto será reprimido con pena privativa de libertad no mayor de tres meses: cuando el embarazo sea consecuencia de violación sexual fuera de matrimonio o inseminación artificial no consentida y ocurrida fuera de matrimonio, siempre que los hechos hubieren sido denunciados o investigados, cuando menos policialmente". Este articulado se encuentra vigente desde el año 1991. Pero, como sostiene Hurtado Pozo, la intención del legislador era despenalizar esta causal de aborto; sin embargo, "esta propuesta fue abandonada de último minuto y sin discusión alguna" en el texto definitivo aprobado, de modo que las indicaciones anotadas son solo circunstancias atenuantes de la represión ${ }^{4}$.

De acuerdo al artículo $100^{\circ}$ del Código Procesal Constitucional, el plazo prescriptorio para interponer una demanda de inconstitucionalidad es de "seis años contado a partir de su publicación" y precisa que "[v]encido los plazos indicados, prescribe la pretensión, sin perjuicio de lo dispuesto por el artículo $51^{\circ}$ y por el segundo párrafo del artículo $138^{\circ}$ de la Constitución", que es la potestad de control difuso de constitucionalidad. Por esta razón, no es posible plantear acción de inconstitucionalidad frente a la norma penal vigente y se apostó por llevar el tema al debate legislativo con miras a una reforma normativa. La vía de la inconstitucionalidad de las normas penales sobre aborto tiene su caso más paradigmático en la demanda ante la Corte

3 "Aborto en tres causales: Cómo el Senado metió al "congelador" la aplaudida promesa de campaña", El Desconcierto, Chile, 14 de junio de 2016. Disponible en: http://www.eldesconcierto.cl/pais-desconcertado/2016/06/14/aborto-en-tres-causalescomo-el-senado-metio-al-congelador-la-aplaudida-promesa-de-campana/ Última fecha de consulta: 30 de octubre de 2016

4 Díaz Colchado, Juan Carlos y Ramírez Huaroto, Beatriz. El aborto y los derechos fundamentales. Análisis de la constitucionalidad de la prohibición penal de la interrupción del embarazo en supuestos de violación sexual y de malformaciones fetales incompatibles con la vida extrauterina, PROMSEX, Lima, 2013, p. 6. 
Constitucional de Colombia, que a través de la Sentencia C-355/06, cuestionó la constitucionalidad de la penalización del aborto en la causal terapéutica, violación sexual y malformaciones congénitas incompatibles con vida extrauterina, por considerarla desproporcionada en tanto "la prevalencia absoluta de la protección de la vida del nasciturus supone un total desconocimiento de la dignidad humana y del libre desarrollo de la personalidad de la mujer gestante ${ }^{\prime \prime 5}$.

En el periodo parlamentario 2006 - 2011 se constituyó la Comisión Especial Revisora del Código Penal, que estuvo presidida por el congresista Torres Caro, la que tuvo como encargo elaborar un Anteproyecto de Código Penal. Esta Comisión propició el debate público sobre diversos temas, entre ellos, la despenalización del aborto cuando el embarazo resulte producto de la violación sexual. Tras un arduo debate con voces especializadas del ámbito médico y jurídico, dicha Comisión decidió despenalizar el aborto en casos de violación. Esta propuesta fue recogida en el Anteproyecto de Ley de Reforma del Nuevo Código Penal; sin embargo, este proceso de Reforma del Código Penal no logró concretarse. Por ello, en el periodo parlamentario 2011-2016, diversas organizaciones en ejercicio del derecho a la participación regulado por Ley 26300, Ley de los derechos de participación y control ciudadanos ${ }^{6}$ impulsaron una Iniciativa Legislativa Ciudadana ${ }^{7}$ para posicionar nuevamente en el Congreso el debate de la despenalización del aborto por violación sexual.

La Iniciativa Legislativa Ciudadana es la prerrogativa que tiene la ciudadanía de proponer un proyecto de ley a fin de este sea discutido en el Congreso. Es la forma más directa de participación política que la ciudadanía encuentra en un sistema democrático. Desde la entrada en vigencia de la ley 26300 hasta el 31 de agosto de este año, la Oficina Nacional de Procesos Electorales vendió 188 Kits Electorales para iniciativas legislativas ciudadanas ${ }^{8}$. De acuerdo a la norma, el proyecto de ley debe contar con un respaldo ciudadano de al menos el $0.3 \%$ de la población electoral nacional; lo que equivale a más de 76 mil firmas válidas. Este tipo de iniciativa legislativa tiene un tratamiento preferencial de trámite en el Congreso; en atención al

5 Sentencia C-355/06 numeral 10.1, emitida en fecha 10 de mayo de 2006.

6 Ley que regula los derechos de participación y establece los mecanismos formales de participación ciudadana en el marco del artículo $2^{\circ}$ inciso 17 de la Constitución Política del Perú.

7 Según Carlos Blancas, la Iniciativa Legislativa Ciudadana es una "concesión a favor de la democracia directa, destinada a permitir la participación de aquellos en la fase inicial o introductora del proceso legislativo". En: Blancas Bustamante, Carlos. Derecho Electoral peruano, Palestra, Lima, 2016, p. 157.

$8 \quad$ Nómina de Kits vendidos disponibles en: https://www.web.onpe.gob.pe/modVentaKits/kit INICIATIVAS.pdf

Última fecha de consulta: 30 de octubre de 2016 
esfuerzo realizado por la ciudadanía, la discusión y votación de la propuesta no debe de superar 120 días después de haberse recibido.

La Iniciativa Legislativa Ciudadana sobre despenalización del aborto (IL 00000142) ${ }^{9}$ llegó al Congreso el 28 de septiembre de 2014 con el apoyo de 64,260 ciudadanos y ciudadanas adherentes, convirtiéndose así en el Proyecto de Ley 3839/2014-IC, que propuso despenalizar el aborto en los casos de embarazos a consecuencia de una violación sexual, inseminación artificial o transferencia de óvulos no consentidos. Fue decretado a la Comisión de Justicia y Derechos Humanos y a la Comisión de Constitución y Reglamento para su estudio y opinión. Las dos Comisiones decidieron archivar el proyecto de ley, la primera de manera definitiva con fecha 6 de julio de 2015 y la segunda el 8 de junio de 2016.

En la Comisión de Justicia y Derechos Humanos el dictamen que recomendó la no aprobación del proyecto, y, por tanto, su archivamiento obtuvo el respaldo de 6 congresistas de 16. El dictamen se fundamentó en tres razones. En primer lugar, la protección absoluta de la vida del concebido. El dictamen señaló "que [se] decide no aprobar el proyecto de ley bajo estudio optimizando el derecho a la vida del concebido y los derechos de las mujeres, considerando que, por regla general, todos los derechos humanos tienen la misma jerarquía y generan las consecuentes obligaciones estatales de respeto y de garantía. En ese sentido, en aplicación de los principios pro personae y pro debiilis, el derecho a la vida del concebido no puede ser sacrificado bajo el argumento de la protección de los derechos de la mujer a la dignidad, al libre desarrollo de la personalidad, a la igualdad y no discriminación y la salud, puesto que en reconocimiento de esos derechos no se prevé tal circunstancia"10 . En segundo lugar, se esgrimió la iniciativa de gasto, pues que el proyecto planteaba la atención integral a las víctimas de violencia sexual, y a consideración de la Comisión, "la propuesta no puede ser aprobada por cuanto encierra la asignación de presupuesto que no se encuentra autorizado por el artículo $79^{\circ}$ de la Constitución Política" ${ }^{11}$. En último lugar, se señaló una razón procedimental por considerar que el contenido de la

$9 \quad$ Número otorgado por la Oficina Nacional de Procesos Electorales.

10 Congreso De La República, Dictamen en mayoría proyecto de ley 3839-2014-IC Comisión de Justicia y Derechos Humanos, 6 de julio de 2015, p.14. Disponible en: http://www2.congreso.gob.pe/Sicr/TraDocEstProc/Contdoc03 2011.nsf/0/1d38a4cc62d0 5e0505257e7b00537499/\$FILE/03839DC15MAY20150607.pdf

Última fecha de consulta: 30 de octubre de 2016

11 Congreso De La República, Dictamen en mayoría proyecto de ley 3839-2014-IC Comisión de Justicia y Derechos Humanos, 6 de julio de 2015, p.15. Disponible en: http://www2.congreso.gob.pe/Sicr/TraDocEstProc/Contdoc03 2011.nsf/0/1d38a4cc62d0 5e0505257e7b00537499/\$FILE/03839DC15MAY20150607.pdf

Última fecha de consulta: 30 de octubre de 2016 
propuesta ya había sido objeto de pronunciamiento al dictaminarse el Nuevo Código Penal.

En la Comisión de Constitución y Reglamento, se preparó un predictamen proponía la aprobación del proyecto de ley bajo dos argumentos. En primer lugar, que tanto el derecho de las mujeres a decidir sobre su propio cuerpo como el derecho a la vida del concebido son bienes constitucionales de la mayor importancia que merecen la protección del Estado de conformidad con el principio derecho a la dignidad, por lo que no sería posible proteger de forma absoluta alguno de estos derechos. $Y$ en segundo lugar, que al no existir otra medida idónea, además del aborto, para optimizar el derecho a la dignidad y el libre desarrollo de la personalidad de las mujeres en los casos de embarazo por violación, inseminación artificial, y transferencia de óvulos no consentida, este debía permitirse pues estos embarazos presentan una característica resaltante: la falta de voluntad de la madre. No obstante, este predictamen obtuvo el respaldo de solo 4 congresistas, mientras que 6 votos contrarios propusieron el archivamiento de la iniciativa.

El tema de la despenalización del aborto también fue debatido en el período parlamentario 2011-2016 en el marco de la reforma del Código Penal, Proyecto de Ley $3491 / 2013-C^{12}$. El dictamen en mayoría de dicho proyecto de ley modificó la pena respecto a la penalización del aborto por violación estableciendo prestación de servicios a la comunidad de 10 a 50 jornadas a la mujer que abortara cuando su embarazo haya sido producto de una violación sexual o una inseminación artificial no consentida, siempre que los hechos hayan sido denunciados o investigados cuando menos policialmente. Esta propuesta punitiva mantenía la finalidad de que la víctima de violencia sexual continuara el embarazo, lo que implica tratar a las mujeres como un medio y no como un fin en sí mismo.

En el actual periodo parlamentario 2016-2021, por Acuerdo 19-2016-2017/CONSEJO$\mathrm{CR}$, adoptado en la cuarta sesión del Consejo Directivo del Congreso de la República se aprobó que "[l]as iniciativas legislativas ciudadanas registradas y en proceso, que fueron presentadas conforme a la Ley 26300, Ley de los derechos de participación y control ciudadanos, continúan su trámite desde el estado procesal al término del período parlamentario 2011-2016; sin embargo, son enviadas, para su estudio y dictamen, a la Comisión o las comisiones actuales homónimas de las del período

12 Última versión del Dictamen en mayoría del proyecto de ley de fecha 04 de marzo de 2016. Disponible en: http://www2.congreso.gob.pe/Sicr/TraDocEstProc/Contdoc03 2011.nsf/ba75101a33765c 2c05257e5400552213/e411339ab0d7d03205257f6c0060ed61/\$FILE/TS0016320160304.p df Última fecha de consulta: 30 de octubre de 2016 
parlamentario precedente que las conocieron o a las que fueron enviadas"13 ${ }^{13}$. En virtud de ello, se ha reingresado al presente período la iniciativa legislativa como el Proyecto de Ley 355/2016-IC ${ }^{14}$. Por su parte, el Frente Amplio por Justicia, Vida y Libertad incluyó como propuesta de campaña la presentación de un proyecto de ley sobre la despenalización del aborto cuyo embarazo sea producto de una violación sexual ${ }^{15}$ y ha anunciado la presentación de una iniciativa legislativa sobre el particular ${ }^{16}$.

\section{Estándares internacionales sobre recursos efectivos para el acceso a los servicios de aborto legal ${ }^{17}$}

A la fecha existen cuatro casos sobre acceso al aborto legal resueltos en los sistemas internacionales de derechos humanos. Especialmente en los que han sido resueltos por Comités monitores de tratados del Sistema de Naciones Unidas queda en evidencia que judicializar el acceso al aborto legal, incluido el proceso de amparo, no reviste el estándar de recurso efectivo ante la violación de derechos fundamentales.

\subsection{K.L. contra el Perú, el primer caso sobre la materia}

La violación de derechos como consecuencia de la negativa estatal a proveer servicios en los casos legales de aborto, fue abordado por primera vez con ocasión del caso de

13 Disponible en: http://www2.congreso.gob.pe/Sicr/ArchGeneral/acuerdosconsejo.nsf/ActaSesion/8DFD52 CE685CFEB00525802D005BA688/\$FILE/cd04-07.set.2016.pdf

Última fecha de consulta: 30 de octubre de 2016 http://www.leyes.congreso.gob.pe/Documentos/2016 2021/Proyectos de Ley y de Res oluciones Legislativas/PL0035520161003.pdf Última fecha de consulta: 30 de octubre de 2016

Esta propuesta fue incluida en el Plan de Gobierno del Frente Amplio por Justicia, Vida y Libertad. Disponible en: http://www.votoinformado.pe/voto/plan-de-gobiernocandidato.aspx?p=3iz9w|xoUauNn0QrROG6mg

Última fecha de consulta: 30 de octubre de 2016

"Frente Amplio impulsará despenalización de aborto por violación", Lima, 28 de septiembre de 2016. Disponible en: http://elcomercio.pe/politica/congreso/frente-amplioimpulsara-despenalizacion-aborto-violacion-noticia-1935214

Última fecha de consulta: 30 de octubre de 2016

Se retoman consideraciones expuestas en Díaz Colchado, Juan Carlos y Ramírez Huaroto, Beatriz. El aborto y los derechos fundamentales. Análisis de la constitucionalidad de la prohibición penal de la interrupción del embarazo en supuestos de violación sexual y de malformaciones fetales incompatibles con la vida extrauterina, PROMSEX, Lima, 2013, pp. 82-90. 
K.L. contra el Perú que fue resuelto por el Comité de Derechos Humanos ${ }^{18}$. K.L. quedó embarazada en marzo de 2001 cuando tenía 17 años de edad y en junio de ese año se diagnosticó que tenía un feto anencefálico por medio de una ecografía realizada en el hospital público en el que se hacía sus controles. El médico gineco-obstetra informó a la adolescente de los riesgos de una gestación de esas características y le informó sobre sus opciones de continuar o interrumpir el embarazo. K.L. decidió interrumpir y su madre presentó una solicitud a la dirección del hospital para tal efecto, la solicitud le fue denegada porque se consideró que se trata de un aborto punible según el artículo $120^{\circ}$ del Código Penal que contemplaba los casos de malformaciones fetales y no uno de tipo no punible según el artículo $119^{\circ}$ que incluye los casos de riesgo para la salud y vida de las gestantes. Dado que el aborto fue negado, K.L. continuó la gestación la que la dejó sumida en una profunda depresión y con necesidad de tratamiento médico por una infección ginecológica.

El Comité acogió las declaraciones médicas que indicaban que un embarazo de feto anencefálico conllevaba un riesgo vital y secuelas psicológicas severas y en esa medida señaló que el Estado peruano violó el artículo $7^{\circ}$ del Pacto Internacional de Derechos Civiles y Políticos (PIDCP $)^{19}$.

El Comité entendió que en la legislación interna estaba permitido que se practiquen abortos en caso de riesgo para la salud de la madre y, a la luz de las pruebas presentadas, determinó que en el caso esas condiciones estaban presentes por lo que la negativa a prestar el servicio violó el artículo $17^{\circ}$ del PIDCP ${ }^{20}$. En tanto no se acreditó que se hubiera brindado a K.L. atención especial por su condición de menor de edad se declaró también una violación al artículo $24^{\circ}$ del Pacto ${ }^{21}$. Por último, la autora alegó que no contó con un recurso adecuado para exigir la garantía de su

18 Comité De Derechos Humanos. CCPR/C/85/D/1153/2003, dictamen aprobado el 24 de octubre de 2005. Disponible en http://www.mimp.gob.pe/files/

Última fecha de consulta: 30 de octubre de 2016

Pacto Internacional de Derechos Civiles y Políticos, artículo 70. Nadie será sometido a torturas ni a penas o tratos crueles, inhumanos o degradantes. En particular, nadie será sometido sin su libre consentimiento a experimentos médicos o científicos.

Pacto Internacional de Derechos Civiles y Políticos, artículo 170. 1. Nadie será objeto de injerencias arbitrarias o ilegales en su vida privada, su familia, su domicilio o su correspondencia, ni de ataques ilegales a su honra y reputación. 2 . Toda persona tiene derecho a la protección de la ley contra esas injerencias o esos ataques.

21 Pacto Internacional de Derechos Civiles y Políticos, artículo 240. 1. Todo niño tiene derecho, sin discriminación alguna por motivos de raza, color, sexo, idioma, religión, origen nacional o social, posición económica o nacimiento, a las medidas de protección que su condición de menor requiere, tanto por parte de su familia como de la sociedad y del Estado. 2. Todo niño será inscrito inmediatamente después de su nacimiento y deberá tener un nombre. 3 . Todo niño tiene derecho a adquirir una nacionalidad. 
derecho a un aborto legal y dado que el Estado no ofreció información en otro sentido se declaró una violación del artículo $2^{22}$.

En el dictamen del caso, además de declarar la violación de los derechos indicados, el Comité de derechos Humanos recordó la obligación del Estado de proporcionar a K.L. un recurso efectivo que incluyera indemnización y la obligación de adoptar medidas para evitar que se cometan violaciones semejantes en el futuro.

\subsection{Paulina contra México}

Posteriormente al caso K.L. en el Sistema Interamericano de Derechos Humanos se resolvió el caso de Paulina Ramírez contra México ${ }^{23}$. En esta petición se argumentó que se violaron los derechos humanos de Paulina al obstaculizarle el ejercicio de su derecho a un aborto legal. En 1999, cuando ella tenía 13 años, fue violada y pese a que en el Estado de Baja California donde vivía se permitía el aborto en casos de violación si se realizaba dentro de los 90 días de gestación y con la autorización del Ministerio Público, ella enfrentó obstáculos por parte de éste órgano para obtener la autorización. Posteriormente, aún con la autorización fiscal, el servicio de salud al que fue derivada no la atendió y a ella y su madre les informaron erradamente sobre las consecuencias de los procedimientos de aborto y las presionaron para que desistieran de su solicitud.

22 Pacto Internacional de Derechos Civiles y Políticos, artículo $2^{\circ} .1$. Cada uno de los Estados Partes en el presente Pacto se compromete a respetar y a garantizar a todos los individuos que se encuentren en su territorio y estén sujetos a su jurisdicción los derechos reconocidos en el presente Pacto, sin distinción alguna de raza, color, sexo, idioma, religión, opinión política o de otra índole, origen nacional o social, posición económica, nacimiento o cualquier otra condición social. 2. Cada Estado Parte se compromete a adoptar, con arreglo a sus procedimientos constitucionales y a las disposiciones del presente Pacto, las medidas oportunas para dictar las disposiciones legislativas o de otro carácter que fueren necesarias para hacer efectivos los derechos reconocidos en el presente Pacto y que no estuviesen ya garantizados por disposiciones legislativas o de otro carácter. 3. Cada uno de los Estados Partes en el presente Pacto se compromete a garantizar que: a) Toda persona cuyos derechos o libertades reconocidos en el presente Pacto hayan sido violados podrá interponer un recurso efectivo, aun cuando tal violación hubiera sido cometida por personas que actuaban en ejercicio de sus funciones oficiales; b) La autoridad competente, judicial, administrativa o legislativa, o cualquiera otra autoridad competente prevista por el sistema legal del Estado, decidirá sobre los derechos de toda persona que interponga tal recurso, y desarrollará las posibilidades de recurso judicial; c) Las autoridades competentes cumplirán toda decisión en que se haya estimado procedente el recurso.

23 Comisión Interamericana De Derechos Humanos. Informe 21/07. Solución amistosa. Petición 161-02, Paulina del Carmen Ramírez Jacinto vs. México. 9 de marzo de 2007. Disponible en http://www.cidh.oas.org/annualrep/2007sp/Mexico161.02sp.htm Última fecha de consulta: 30 de octubre de 2016 
La Comisión no emitió informe de admisibilidad, pero propició un acuerdo de solución amistosa que fue suscrito el 8 de marzo de 2006 y publicado el 9 de marzo de 2007. En este acuerdo, el Estado reconoció su responsabilidad internacional y se comprometió a dar medidas de reparación individual para Paulina y su hijo. Se reconoció una indemnización por daño emergente y moral, se aseguró la atención en salud física y psicológica para ella y su hijo y se comprometieron apoyos para la educación del niño y para que Paulina pudiera desarrollar una microempresa. El Estado hizo un "Reconocimiento Público de Responsabilidad" que fue publicado en dos diarios. Asimismo, el Gobierno de Baja California se comprometió a impulsar las propuestas legislativas presentadas por las peticionarias y a calendarizar cursos de capacitación; mientras que el Estado nacional se obligó a realizar una encuesta para evaluar la aplicación de la norma sobre atención médica a la violencia familiar y actualizarla para incluir el abordaje a la violencia sexual que ocurre fuera del contexto familiar, así como realizar un diagnóstico de la información existente sobre el aborto en México.

En el acuerdo de solución amistosa se dio un reconocimiento explícito de que la denuncia de las peticionarias sobre "la falta de una regulación que establezca el procedimiento para ejercer el derecho a interrumpir un embarazo como consecuencia de una violación" era fundada. En el pronunciamiento publicado en un diario oficial el 10 de febrero de 2006 el Estado señaló que:

Como parte de este acuerdo, el Gobierno del Estado de Baja California, presenta este pronunciamiento público, reconociendo que la falta de un adecuado marco normativo en la entidad en materia de aborto generó la violación de los derechos humanos de Paulina del Carmen Ramírez Jacinto.

\subsection{L.M.R. contra la Argentina}

El Comité de Derechos Humanos resolvió en marzo de 2011 otro caso relativo a falta de provisión de servicios de aborto legal ${ }^{24}$. L.M.R. son las iniciales de una joven con discapacidad mental permanente a la que en junio de 2006 se le diagnosticó un embarazo frente a lo cual su madre solicitó la interrupción del mismo. Un hospital se negó a practicar el aborto y remitió a L.M.R. a otro hospital y solicitó que se haga una denuncia policial previamente. Hecha la denuncia contra un tío suyo se le internó en el segundo hospital donde se solicitó una reunión del Comité de Bioética para que emitiera opinión. En el curso de los procedimientos pre-quirúrgicos se emitió una orden judicial para impedir el aborto que fue confirmada en apelación. Esta sentencia fue dejada sin efecto por la Corte Suprema de Justicia de Buenos Aires en julio de 2006, casi mes y medio después de que se denunciara la violación y se solicitara la interrupción legal del embarazo. Pese a que este órgano judicial indicó al hospital que

24 Comité De Derechos Humanos. CCPR/C/101/D/1608/2007, dictamen aprobado el 29 de marzo de 2011. Disponible en http://cladem.org/

Última fecha de consulta: 30 de octubre de 2016 
la intervención era legal y no requería de autorización judicial, el centro médico y la familia de L.M.R. recibieron múltiples presiones para no concretar el procedimiento y, finalmente, el hospital se negó a proveer el servicio por el estado de gestación de más de 20 semanas. El aborto se realizó en agosto de 2006 de forma clandestina por la negativa de otros hospitales y centros de salud.

El Comité consideró que la omisión estatal de no proveer el servicio de aborto, legal conforme a la legislación vigente, cuando éste fue solicitado causó a L.M.R. un sufrimiento físico y moral agravado por su condición de discapacidad que violó el artículo 70 del Pacto Internacional de Derechos Civiles y Políticos (PIDCP) que señala que "[n]adie será sometido a torturas ni a penas o tratos crueles, inhumanos o degradantes".

Asimismo, determinó que los hechos y en particular las decisiones judiciales sobre una materia que debió ser resuelta en la esfera médica constituyeron una violación del artículo $17^{\circ} .1$ que señala que: "Nadie será objeto de injerencias arbitrarias o ilegales en su vida privada, su familia, su domicilio o su correspondencia, ni de ataques ilegales a su honra y reputación.

El Comité señaló que pese a que los recursos judiciales promovidos fueron resueltos finalmente de forma favorable, esto pasó luego de tres instancias lo que implicó que el embarazo se prolongara varias semanas con consecuencias para la salud de L.M.R. y con impacto también en que los hospitales se negaran a prestar el servicio que finalmente se realizó en forma clandestina. Se declaró que todo ello configuró una violación del artículo $2^{\circ}$, párrafo 3 del PIDCP, todo en relación con los artículos $3{ }^{\circ}, 70$ y 170 del Pacto. El Comité considera que la violación del artículo $3^{25}$ está relacionada a los otros artículos por lo que opta por analizarla conjuntamente con éstos.

En este dictamen también, además de declarar la violación de los derechos indicados, el Comité de derechos Humanos recordó la obligación del Estado de proporcionar a L.M.R. un recurso efectivo que incluyera indemnización y la obligación de adoptar medidas para evitar que se cometan violaciones semejantes en el futuro.

\subsection{L.C. contra el Perú}

El último ejemplo de responsabilidad internacional por falta de prestación de servicios de aborto en casos despenalizados también es contra el Perú ${ }^{26}$. L.C. son las iniciales de

25 Pacto Internacional de Derechos Civiles y Políticos, artículo 30. Los Estados Partes en el presente Pacto se comprometen a garantizar a hombres y mujeres la igualdad en el goce de todos los derechos civiles y políticos enunciados en el presente Pacto.

Comité para la Eliminación de la Discriminación contra la Mujer. CEDAW/C/50/D/22/2009, dictamen aprobado el 17 de octubre de 2011 . Disponible en http://www2.ohchr.org/english/law/docs/CEDAW-C-50-D-22-2009 sp.pdf

Última fecha de consulta: 30 de octubre de 2016 
una adolescente víctima de violación sexual que cuando tenía 13 años quedó embarazada como consecuencia de las agresiones y que por ello intento suicidarse el 31 de marzo de 2007 lanzándose al vacío desde el techo de su casa. Trasladada a un hospital público se le diagnosticó "traumatismo vertebromedular cervical, luxación cervical y sección medular completa" con "riesgo de discapacidad permanente" y "riesgo de deterioro de integridad cutánea resultante de la inmovilidad física". Frente a este panorama se recomendó una intervención quirúrgica para evitar que se consolidara el daño sufrido, la misma que se programó para el 12 de abril de 2007. Sin embargo, dado que antes se supo por medio de la evaluación psicológica que L.C. había sido abusada sexualmente y que fue su miedo sobre el embarazo lo que motivó su intento de suicidio, se constató clínicamente el embarazo y por eso razón se suspendió la operación quirúrgica programada. Pese a que la madre de la adolescente solicitó formalmente a la Dirección del hospital un aborto terapéutico que permitiera la realización de la intervención, el pedido fue desestimado por la Junta Médica 42 días después de presentada la solicitud, en el entendido que la vida de la paciente no estaba en riesgo, sin considerar el estado de deterioro de su salud física y mental. La Defensoría del Pueblo solicitó a la Comisión de Alto Nivel de Salud Reproductiva del Colegio Médico del Perú un informe del caso en que se señaló que la salud física y mental de la L.C. estaba en grave riesgo lo que justificaría un aborto terapéutico si se solicitara. Con base a esta documentación, la madre de la adolescente pidió la reconsideración de la negativa a la interrupción de la gestación la misma que fue respondida 20 días después de forma negativa. En el ínterin, L.C. sufrió un aborto espontáneo y sólo después de eso se programó la operación para sus lesiones de columna, la que se realizó casi tres meses y medio después de que se decidiera la necesidad de la misma. Pese a que L.C. debía acceder a una terapia de rehabilitación intensiva, ésta no comenzó sino cuatro meses después, siendo sufragada por su familia, y no ha sido constante por su falta de recursos económicos.

El Comité para la Eliminación de la Discriminación contra la Mujer consideró que la falta de acceso a un procedimiento eficaz y accesible que permitiese a la adolescente establecer su derecho a los servicios de salud física y mental que requería - lo que incluía el aborto terapéutico y la operación de la columna- constituyó una violación del artículo 12 de la Convención sobre la Eliminación de todas las formas de Discriminación contra la Mujer que protege el derecho a la salud ${ }^{27}$, violación agravada por la edad y por la condición de víctima de violación sexual.

Convención sobre la Eliminación de todas las formas de Discriminación contra la Mujer, artículo $12^{\circ}$. 1. Los Estados Partes adoptarán todas las medidas apropiadas para eliminar la discriminación contra la mujer en la esfera de la atención médica a fin de asegurar, en condiciones de igualdad entre hombres y mujeres, el acceso a servicios de atención médica, inclusive los que se refieren a la planificación de la familia. 2 . Sin perjuicio de lo dispuesto en el párrafo 1 supra, los Estados Partes garantizarán a la mujer servicios apropiados en relación con el embarazo, el parto y el período posterior al parto, 
Asimismo, el Comité consideró que la decisión de aplazar la intervención quirúrgica debido al embarazo estuvo influenciada por el estereotipo de que la protección feto debe prevalecer sobre la salud de la madre lo que constituyó una violación del artículo 5 de la Convención que señala la obligación estatal de modificar patrones socioculturales discriminatorios ${ }^{28}$. Por último, el Comité dictaminó que L.C. no dispuso de un recurso efectivo que le permitiera resguardar su salud por medio de la solicitud del aborto terapéutico, legal en el Perú, lo que constituyó una violación conjunta del artículo 2 incisos c) y f) ${ }^{29}$ y del artículo $3^{30}$ de la Convención que señalan la obligación del Estado de adoptar todas las medidas adecuadas para garantizar la protección de las mujeres contra actos de discriminación y para modificar o derogar leyes que constituyan discriminación contra la mujer. En el dictamen se señaló que estos artículos han sido vulnerados conjuntamente con el artículo 1 que recoge la definición de discriminación basada en sexo ${ }^{31}$.

proporcionando servicios gratuitos cuando fuere necesario y le asegurarán una nutrición adecuada durante el embarazo y la lactancia.

Convención sobre la Eliminación de todas las formas de Discriminación contra la Mujer, artículo $5^{\circ}$. Los Estados Partes tomarán todas las medidas apropiadas para: a) Modificar los patrones socioculturales de conducta de hombres y mujeres, con miras a alcanzar la eliminación de los prejuicios y las prácticas consuetudinarias y de cualquier otra índole que estén basados en la idea de la inferioridad o superioridad de cualquiera de los sexos o en funciones estereotipadas de hombres y mujeres; b) Garantizar que la educación familiar incluya una comprensión adecuada de la maternidad como función social y el reconocimiento de la responsabilidad común de hombres y mujeres en cuanto a la educación y al desarrollo de sus hijos, en la inteligencia de que el interés de los hijos constituirá la consideración primordial en todos los casos.

Convención sobre la Eliminación de todas las formas de Discriminación contra la Mujer, artículo $2^{\circ}$. Los Estados Partes condenan la discriminación contra la mujer en todas sus formas, convienen en seguir, por todos los medios apropiados y sin dilaciones, una política encaminada a eliminar la discriminación contra la mujer $y$, con tal objeto, se comprometen a: [...] c) Establecer la protección jurídica de los derechos de la mujer sobre una base de igualdad con los del hombre y garantizar, por conducto de los tribunales nacionales o competentes y de otras instituciones públicas, la protección efectiva de la mujer contra todo acto de discriminación; [...] f) Adaptar todos las medidas adecuadas, incluso de carácter legislativo, para modificar o derogar leyes, reglamentos, usos y prácticas que constituyan discriminación contra la mujer.

Convención sobre la Eliminación de todas las formas de Discriminación contra la Mujer, artículo $3^{\circ}$. Los Estados Partes tomarán en todas las esferas, y en particular en las esferas política, social, económica y cultural, todas las medidas apropiadas, incluso de carácter legislativo, para asegurar el pleno desarrollo y adelanto de la mujer, con el objeto de garantizarle el ejercicio y el goce de los derechos humanos y las libertades fundamentales en igualdad de condiciones con el hombre.

Convención sobre la Eliminación de todas las formas de Discriminación contra la Mujer, artículo $1^{\circ}$. A los efectos de la presente Convención, la expresión "discriminación contra la mujer" denotará toda distinción, exclusión a restricción basada en el sexo que tenga 
Sobre la base de estas consideraciones, el Comité formuló al Estado peruano las siguientes recomendaciones:

a. Proporcionar a L.C. medidas de reparación que incluyan una indemnización adecuada por daños morales y materiales así como medidas de rehabilitación acordes a la gravedad de la violación de sus derechos y de su estado de salud.

b. Establecer un mecanismo para el acceso efectivo al aborto terapéutico en condiciones que protejan la salud física y mental de las mujeres e impidan que en el futuro se produzcan violaciones similares a las del presente caso.

c. Tomar medidas en relación a los derechos reproductivos que sean conocidas y respetadas en todos los centros sanitarios lo que incluye i) programas de enseñanza y formación para que las y los profesionales de salud cambien sus actitudes y comportamientos en relación a las adolescentes que desean recibir servicios de salud reproductivas y que respondan a sus necesidades específicas relacionadas con la violencia sexual y ii) directrices o protocolos para garantizar la disponibilidad y acceso a servicios de salud públicos.

d. Examinar la interpretación restringida del aborto terapéutico.

e. Revisar la legislación para despenalizar el aborto cuando el embarazo tenga como causa una violación sexual.

\section{5 ¿Los procesos judiciales son recursos efectivos para la garantía del derecho el acceso al aborto legal?}

El derecho al acceso al aborto legal "se trata de un derecho temporal, que marca su naturaleza especial, pues el procedimiento de la interrupción del embarazo tiene un periodo cierto dentro del cual debe ser practicado. El aborto solo puede proceder, como un reloj en cuenta regresiva, desde que la mujer queda embarazada hasta antes del nacimiento (...) su atención no puede dilatarse ${ }^{\prime 32}$.

En los tres casos tramitados ante el Sistema de Naciones Unidas se aprecia que se consideró que los Estados no ofrecían recursos judiciales efectivos para garantizar el

por objeto o por resultado menoscabar o anular el reconocimiento, goce o ejercicio por la mujer, independientemente de su estado civil, sobre la base de la igualdad del hombre y la mujer, de los derechos humanos y las libertades fundamentales en las esferas política, económica, social, cultural y civil o en cualquier otra esfera.

Guzmán Rodríguez, Diana Esther y Chaparro González, Nina. Los remedios que da el derecho. El papel del juez constitucional cuando la interrupción del embarazo no se garantiza. DEJUSTICIA, Bogotá, 2016. p. 43. Disponible en: http://www.dejusticia.org/files/r2 actividades recursos/fi name recurso.794.pdf Última fecha de consulta: 30 de octubre de 2016 
acceso al aborto legal. Concretamente en los casos litigados contra el Estado peruano, las partes demandantes argumentaron que los procesos constitucionales de amparo, aun cuando su naturaleza procesal es la protección urgente de los derechos fundamentales, no calificaban como recurso efectivo puesto que su tiempo real es excesivamente largo y, ante los efectos del paso del tiempo en la gestación, esta vía se convertía en no satisfactoria para la tutela de los derechos fundamentales de las mujeres.

Así por ejemplo en el caso $\mathrm{LC}^{33}$, la defensa de la víctima argumentó lo siguiente:

"2.15 El recurso de amparo constitucional no cumple con el requisito temporal necesario para asegurar la efectividad de la acción. De acuerdo a las normas reguladoras de este procedimiento, para contar con una decisión en firme se requieren aproximadamente entre 62 y 102 días corrientes, después de que se hayan agotado las vías previas. Además, la procedencia del recurso se encuentra sujeta al agotamiento de esas vías previas, en este caso la negativa por parte del hospital de realizar la interrupción. En el caso de L.C., este término excedía el plazo para que efectivamente pudiera gozar del derecho sin arriesgar aún más su vida y su salud. Cuando recibió la primera negativa para acceder al aborto ya estaba en su $16^{\mathrm{a}}$ semana de embarazo y cuando se resolvió el recurso habría estado en la $20^{\mathrm{a}}$. Acudir al recurso de amparo después de este tiempo no habría tenido sentido pues, para el momento probable en que se hubiera producido una decisión firme y ejecutable, L.C. habría estado embarazada de más de 28 semanas. Además, si bien las normas establecen un procedimiento que en teoría debería durar entre 62 y 102 días aproximadamente, la realidad es otra, pues los procesos de amparo generalmente tardan años en resolverse. En este sentido, la autora recuerda el dictamen del Comité de Derechos Humanos en el caso K. N. L. H. c. el Perú, relativo igualmente a la negativa de practicar un aborto terapéutico a una mujer embarazada de un feto anencefálico, en que el Comité no consideró el recurso de amparo como un recurso eficaz que debiera agotarse."

El Estado, por su parte, argumentó que debió seguirse un proceso de amparo en la vía interna argumentando que "con arreglo al artículo 53 del Código Procesal Constitucional, la sentencia debe dictarse en la misma audiencia o, excepcionalmente, en un plazo que no excederá de cinco días después de concluida esta. De haber apelación, la sentencia relativa a la misma debe dictarse dentro de los cinco días posteriores a la vista de la causa" (numeral 4.3).

En su análisis respecto de la admisibilidad de la petición, el Comité CEDAW precisó la impertinencia del amparo para casos de falta de acceso al aborto legal:

33 Comité Para la Eliminación de la Discriminación contra la Mujer. CEDAW/C/50/D/22/2009, dictamen aprobado el 17 de octubre de 2011 . Disponible en http://www2.ohchr.org/english/law/docs/CEDAW-C-50-D-22-2009 sp.pdf

Última fecha de consulta: 30 de octubre de 2016 
"8.4 [...] Además, no considera razonable exigir a la autora que acudiera ante las autoridades judiciales para intentar un procedimiento cuya duración era impredecible. El carácter impredecible se aprecia no solo por la vaguedad de la propia ley en cuanto a los plazos que establece en materia de recurso de amparo, sino también por el hecho de que la celeridad del mismo no puede demostrarse en base a precedentes jurisprudenciales, según ponen en evidencia las informaciones proporcionadas por las partes. El Comité considera que la víctima no tuvo a su disposición ningún procedimiento legal adecuado que le diera acceso a una decisión preventiva, independiente y ejecutoria. En consecuencia, concluye que la excepción al agotamiento de los recursos de la jurisdicción interna prevista en el artículo 4, párrafo 1, del Protocolo Facultativo, relativa a la improbabilidad de que el recurso de amparo brindara un remedio efectivo a la víctima, es aplicable en el presente caso."

Con esta argumentación también el Comité consideró en el análisis de fondo que no se contó con un recurso efectivo:

"8.16 En relación con las alegaciones de una posible violación de los artículos 2 c) y f), el Comité recuerda su jurisprudencia con arreglo a la cual, si bien reconoce que el texto de la Convención no hace referencia expresa al derecho a un recurso, considera que ese derecho queda implícito, en particular en el artículo 2 c), conforme al cual los Estados partes se comprometen a "establecer la protección jurídica de los derechos de la mujer sobre una base de igualdad con los del hombre y garantizar, por conducto de los tribunales nacionales o competentes y de otras instituciones públicas, la protección efectiva de la mujer contra todo acto de discriminación". Además, en virtud del artículo 2 f) leído conjuntamente con el artículo 3, el Estado parte está obligado a adoptar todas las medidas adecuadas, incluso de carácter legislativo, para modificar o derogar leyes existentes que constituyan discriminación contra la mujer. [...] Además, como ya se ha indicado anteriormente, el recurso de amparo no constituía una vía judicial eficaz para proteger el derecho de la autora a la atención médica adecuada $[\ldots]^{\prime \prime}$.

Así, existe un estándar a considerar que ningún tipo de proceso judicial debe ser requerido para acceder a servicios legales de aborto. El derecho al acceso al aborto legal supone que:

"las mujeres que abortan dentro de las causales despenalizadas no pueden ser criminalizadas y además tienen el derecho de acceder a los servicios de salud necesarios para que puedan ejercer su derecho. Esto, implica, entonces, que el Estado tiene obligaciones concretas "de hacer", destinadas a garantizar dicho derecho a acceder a la IVE (aborto legal) en condiciones que permitan la garantía efectiva e integral de sus derechos sexuales y reproductivos. En este sentido, de acuerdo con los estándares internacionales [...] el Estado está obligado a garantizar la existencia de 
procedimientos seguros, económicos y oportunos, así como a remover los obstáculos que puedan enfrentar las mujeres para acceder a ellos ${ }^{\prime 34}$.

Y esto se ha considerado también en los pronunciamientos de Derecho Comparado. Es el caso de la sentencia de la Corte Suprema de Justicia de la Nación Argentina que se pronunció sobre la despenalización del aborto en casos de violación sexual ${ }^{35}$. Este caso se basó en la medida autosatisfactiva que puso la señora madre A. F. en representación su hija de 15 años de edad, A.G. Previamente, la señora A.F. solicitó a la justicia penal de la Provincia del Chubut que se dispusiera la interrupción del embarazo de la niña adolescente; el juez penal de la causa sostuvo que carecía de facultades para adoptar medidas como la solicitada durante la etapa de la investigación, por lo que ordenó el pase de las actuaciones a la fiscalía y ésta declaró que ese fuero no era competente para resolver el pedido. Por esto, la madre de A.G. inició una medida autosatisfactiva, que es un tipo de solución jurisdiccional prevista en el Derecho argentino y que procede para causas "urgentes, autónomas, despachables inaudita pars y mediando una fuerte probabilidad de que los planteos formulados sean atendibles"; es un requerimiento "urgente formulado al órgano jurisdiccional que se agota con su despacho favorable, no siendo necesaria acción ulterior principal para evitar su caducidad o decaimiento" ${ }^{\prime \prime 36}$.

La Corte argentina aclaró que, no obstante que el aborto ya se había realizado en el circuito clandestino, le correspondía pronunciarse en el proceso de la medida autosatisfactiva debido a que el tiempo que implica el trámite judicial de cuestiones de esta naturaleza excede el que lleva su decurso natural (el de la gestación), que era necesario el dictado de un pronunciamiento que pudiera servir de guía para la solución de futuros casos análogos y que estaba comprometida la responsabilidad internacional del Estado Argentino. Así, tras un análisis del derecho a la dignidad y el libre desarrollo de la personalidad, amplió la interpretación de la norma penal ${ }^{37}$ para declarar no

34 Guzmán Rodríguez, Diana Esther y Chaparro González, Nina. Los remedios que da el derecho. El papel del juez constitucional cuando la interrupción del embarazo no se garantiza. DEJUSTICIA, Bogotá, 2016. p. 42. Disponible en: http://www.dejusticia.org/files/r2 actividades recursos/fi name recurso.794.pdf Última fecha de consulta: 30 de octubre de 2016

Sentencia en la causa F., A.L. s/ medida autosatisfactiva, del 13 de marzo de 2012.

Cavagnaro, María Victoria. "Nuevas respuestas en el Derecho de Familia: Las medidas autosatisfactivas". Sistema Argentino de Información Jurídica, marzo de 2009. Disponible en http://www.infojus.gob.ar/maria-victoria-cavagnaro-nuevas-respuestas-derechofamilia-medidas-autosatisfactivas-dacf090010-2009-03/123456789-0abc-defg0100gofcanirtcod Última fecha de consulta: 30 de octubre de 2016

37 Artículo 860, inciso 2, del Código Penal Argentino: $2^{\circ}$ Si el embarazo proviene de una violación o de un atentado al pudor cometido sobre una mujer idiota o demente. En este caso, el consentimiento de su representante legal deberá ser requerido para el aborto. 
punible el aborto de todas las víctimas de violación sexual, sin excepción, ya que la norma sugería que se encontraba despenalizado solo en los casos en el que la víctima tuviera la condición de "idiota o demente".

En la sentencia, la Corte Suprema argentina expresamente consideró que en ningún caso los profesionales de salud pueden condicionar la realización del procedimiento del aborto a una autorización judicial, puesto que ello constituiría un obstáculo al acceso a una práctica legal:

19) [...] La judicialización de esta cuestión, que por su reiteración constituye una verdadera práctica institucional, además de ser innecesaria e ilegal, es cuestionable porque obliga a la víctima del delito a exponer públicamente su vida privada, y es también contraproducente porque la demora que apareja en su realización pone en riesgo tanto el derecho a la salud de la solicitante como su derecho al acceso a la interrupción del embarazo en condiciones seguras.

Llegado este punto, el Tribunal considera ineludible destacar que, a pesar de que el Código Penal argentino regula desde hace noventa años diferentes supuestos específicos de despenalización del aborto, como el traído a discusión ante este Tribunal (artículo 86 , inciso ${ }^{\circ}$ ), se sigue manteniendo una práctica contra legem, fomentada por los profesionales de la salud y convalidada por distintos operadores de los poderes judiciales nacionales como provinciales, que hace caso omiso de aquellos preceptos, exigiendo allí donde la ley nada reclama, requisitos tales como la solicitud de una autorización para practicar la interrupción del embarazo producto de una violación lo que, como en el caso, termina adquiriendo características intolerables a la luz de garantías y principios constitucionales y convencionales que son ley suprema de la Nación.

20) Que es debido a ello que este Tribunal se ve forzado a tener que recordar, tanto a profesionales de la salud como a los distintos operadores de los diferentes poderes judiciales nacionales o provinciales, que por imperio del artículo 19 in fine de la Constitución Nacional, que consagra el principio de reserva como complemento de la legalidad penal, ha quedado expresamente dicho por voluntad del constituyente que "ningún habitante de la Nación será obligado a hacer lo que no manda la ley, ni privado de lo que ella no prohíbe".

21) Que teniendo a la luz aquella manda constitucional es que debe interpretarse la letra del artículo 86 , inciso $2^{\circ}$, del Código Penal y por dicha razón, se debe concluir que quien se encuentre en las condiciones allí descriptas, no puede ni debe ser obligada a solicitar una autorización judicial para interrumpir su embarazo, toda vez que la ley no lo manda, como tampoco puede ni debe ser privada del derecho que le asiste a la interrupción del mismo ya que ello, lejos de estar prohibido, está permitido y no resulta punible. 
Por su parte, la Corte Constitucional de Colombia, instancia que a la fecha ha emitido 6 fallos en materia de acceso al aborto legal ${ }^{38}$, después que despenalizara el aborto en sus tres causales en el año $2006^{39}$, ha desarrollado importantes estándares de acceso al aborto legal en los servicios de salud los mismos que giran alrededor de los principios de oportunidad, calidad y seguridad.

En la Sentencia T-841/11 como resultado de la tutela interpuesta por la madre de una niña de 12 años debido a la falta de respuesta de los servicios de salud frente a su solicitud de acceso a un aborto legal por la afectación a su salud mental que la gestación ocasionaba, determinó que el Sistema de Salud debe garantizar el acceso oportuno al aborto legal en un plazo razonable:

"[...] la Superintendencia Nacional de Salud que, por los medios que considere efectivos y adecuados, informe a las empresas promotoras de salud y las instituciones prestadoras de salud que: Deben responder de forma oportuna las solicitudes de IVE y que un término razonable para ello y para realizar su práctica- de ser médicamente posible-es de (5) días."

Asimismo, en la Sentencia T-532/14, caso en el que la Corte analizó la tutela interpuesta por CAM de 31 años contra diversos servicios de salud privados por no haberle prestado el servicio de interrupción voluntaria del embarazo, la Corte consideró que:

"[...] en los casos de interrupción voluntaria del embarazo que fueron despenalizados en la precitada sentencia, es deber de las autoridades públicas y de los particulares que actúan en esa calidad -las empresas promotoras de salud y las instituciones prestadoras de salud-, remover las barreras y los obstáculos que impidan a las mujeres gestantes acceder al servicio de IVE en condiciones de calidad y seguridad."

Sobre la eficacia de la Tutela en la garantía del derecho al acceso al aborto legal, la Corte Constitucional de Colombia, en los 6 casos que examinó, consideró que se vulneró el derecho a la intervención voluntaria del embarazo por cuanto se les impidió a las accionantes acceder de manera oportuna a los procedimientos médicos necesarios para la interrupción. Según el análisis realizado por Guzmán y Chaparro "dichos obstáculos provienen de dilaciones y trabas generadas por quienes estaban

38 Sentencias T 988-2007, T-946 de 2008, T-209- de 2008, T-841 de 2011, T-585-2010 y T532-2014

39 Corte Constitucional de Colombia. Sentencia C-355 de 2006. Despenaliza el aborto i) Cuando la continuación del embarazo constituya peligro para la vida o la salud de la mujer, ii) cuando exista grave malformación del feto que haga inviable su vida; y iii) cuando el embarazo sea el resultado de una conducta constitutiva de acceso carnal o acto sexual sin consentimiento, abusivo o de inseminación artificial o transferencia de óvulo fecundado no consentidas, 0 de incesto. Disponible en: http://www.corteconstitucional.gov.co/relatoria/2006/C-355-06.htm Última fecha de consulta: 30 de octubre de 2016 
encargados de prestar el servicio directamente o de la negativa de los jueces de primera o segunda instancia que conocieron la acción de tutela interpuesta por las accionantes $^{\prime 40}$.

En la mayoría de casos cuando las acciones de tutela fueron examinadas por la Corte esta declaró carencia actual del objeto por daño consumado ${ }^{41}$ ya sea porque la gestación culminó en nacimiento o las accionantes accedieron de manera clandestina a una interrupción del embarazo:

"[...] el daño vendría dado por la circunstancia de que la mujer no tuvo la posibilidad de acceder a un servicio que debía serle prestado en un espacio de tiempo determinado, agotado el cual, éste resulta de imposible satisfacción".

Por este motivo, la Corte, al momento de analizar los casos, "ordenó un conjunto amplio de remedios judiciales (...) ordenó medidas de reparación indemnizatorias, atención médica y sanción a los responsables ${ }^{\prime 42}$. Pasando a convertirse la tutela constitucional colombiana de un proceso de garantía de derechos fundamentales a una tutela de remedio de tipo indemnizatoria.

Por lo anteriormente expuesto, concluimos que los recursos judiciales no constituyen vías idóneas y efectivas para la garantizar el acceso a un aborto legal, puesto que son en sí mismos limitan el acceso oportuno a este servicio vulnerando los derechos fundamentales de las mujeres, derechos que precisamente son los que persigue proteger la legalidad del aborto. El desarrollo jurisprudencial comparado va por la línea de eliminar los obstáculos o requisitos que podrían afectar el acceso efectivo al aborto legal en un estándar de oportunidad, calidad y seguridad.

\section{Reflexiones finales ¿Los procesos constitucionales pueden ser recursos efectivos para el acceso a los supuestos de aborto aún penalizados?}

Como se ha mencionado, para cambiar la penalización del aborto en el Perú se ha priorizado la vía legislativa en la medida de las restricciones formales existentes para la interposición de un proceso de inconstitucionalidad respecto de la norma vigente. En caso de que se aprobara una nueva ley que modificara la regulación del aborto, esta sí podría ser pasible de una acción de inconstitucionalidad dentro del plazo establecido.

Por otro lado, conforme se ha revisado, es un estándar internacional que para el acceso a la interrupción legal de un embarazo no debe requerirse trámite por la vía

40 Guzmán Rodríguez, Diana Esther y Chaparro González, Nina. 2015, p.13.

41

Sentencia

T-532/2014.

Disponible

en:

http://www.corteconstitucional.gov.co/relatoria/2014/t-532-14.htm

Última fecha de consulta: 30 de octubre de 2016

42

Guzmán Rodríguez, Diana Esther y Chaparro González, Nina. 2015, p.21. 
judicial alguna. El proceso constitucional peruano de amparo ha sido desestimado como recurso efectivo para el acceso al aborto que es legal, por lo que se ha requerido una intervención sanitaria, que se hizo efectiva en junio de 2014 a través de la Guía Técnica Nacional para la estandarización del procedimiento de la atención integral de la gestante en la Interrupción Voluntaria por indicación terapéutica del embarazo menor de 22 semanas con consentimiento informado en el marco de lo dispuesto en el artículo $119^{\circ}$ del Código Penal, aprobada por Resolución Ministerial 486-2014/MINSA.

A la fecha no existe jurisprudencia internacional sobre acceso al aborto en casos penalizados en la legislación interna. Frente a los supuestos de aborto aún penalizados en el Perú, como el aborto en casos de violación sexual, ningún proceso ha sido interpuesto en la jurisdicción nacional. De hacerlo, una mujer que busca acceder a una prestación semejante requiere apelar a la inaplicación por control difuso de la norma penal vigente destacando la vulneración de sus derechos fundamentales en juego ${ }^{43}$. Los procesos constitucionales de hábeas corpus y amparo podrían ser esta vía en atención a los derechos que protegen de acuerdo a nuestra regulación vigente. El proceso de hábeas corpus procede ante la acción u omisión que amenace o vulnere los derechos asociados a la libertad individual como la integridad personal, y el derecho a no ser sometido a tortura o tratos inhumanos o humillantes, ni violentado para obtener declaraciones ${ }^{44}$, derecho que ha sido considerado vulnerado en los casos de acceso al aborto resueltos en las instancias internacionales, como se ha señalado en los dictámenes de los casos K.L. contra Perú y L.M.R. contra Argentina. Por su parte, el proceso de amparo procede en defensa de derechos como el de igualdad y no discriminación por razón ${ }^{45}$, derecho que está en juego en la penalización del aborto como se ha señalado a propósito del caso L.C.

En la práctica, los plazos de los procesos constitucionales son un escollo para un acceso efectivo, pero podrían sentar un precedente respecto del acceso para causas semejantes en el futur ${ }^{46}$. Este tipo de acciones, sin duda, entran de lleno en el debate sobre los alcances de la justicia en un Estado Constitucional de Derecho; debate que, dados los estándares mínimos de reconocimiento de derechos reproductivos en el Perú, debiera darse.

\footnotetext{
43 Código Procesal Constitucional, artículo $3^{\circ}$.

44 Código Procesal Constitucional, artículo $25^{\circ}$.

45 Código Procesal Constitucional, artículo $37^{\circ}$.

46 Código Procesal Constitucional, artículo 10, segundo párrafo.
} 